\title{
Interim Canadian Recommendations for the use of fractional dose of yellow fever vaccine during a vaccine shortage: Now in effect
}

Committee to Advise on Tropical Medicine and Travel (CATMAT) ${ }^{1 *}$

\author{
Affiliation \\ ${ }^{1}$ Travel Health, Public Health Agency of Canada, Ottawa, ON \\ *Correspondence: CATMAT.Secretariat@phac-aspc.gc.ca
}

Suggested citation: Committee to Advise on Tropical Medicine and Travel. Interim Canadian Recommendations for the use of fractional dose of yellow fever during a vaccine shortage: Now in effect. Can Commun Dis Rep. 2017;43(2):59. https://doi.org/10.14745/ccdr.v43i02a05

The licensed marketer of the yellow fever vaccine in Canada is experiencing a supply issue for the Yellow Fever vaccine licenced for use in Canada. In an effort to manage the supply shortage, the manufacturer is rationing vaccine to designated Yellow Fever Vaccine Centres, currently fulfilling orders at approximately $50 \%$ of the normal requirement. A return to normal supply is only anticipated in late 2018. As a result, some rationing is expected to continue until that time.

To minimize the impact of the shortage, the Public Health Agency of Canada is continuing to work with the manufacturer to ensure that limited supplies of vaccine are equitably distributed across the country.

Given the current yellow fever vaccine shortage in Canada, the Public Health Agency of Canada encourages health care practitioners to refer to the Interim Canadian recommendations for the use of fractional dose of yellow fever vaccine during a vaccine shortage (1) developed by the Committee to Advise of Tropical Medicine and Travel (CATMAT). The statement outlines interim recommendations intended for use during a yellow fever vaccine shortage, which differ from the standard recommendations for yellow fever vaccination in the Canadian Immunization Guide, and in the Committee to Advise on Tropical Medicine and Travel (CATMAT) Statement for Travellers and Yellow Fever.

\section{Reference}

1. Yellow Fever Working Group on behalf of the Committee to Advise on Tropical Medicine and Travel (CATMAT). Interim Canadian Recommendations for the use of a fractional dose of yellow fever during a vaccine shortage. Can Commun Dis Rep. 2016;42(8):158-60. Available from: http://www.phac-aspc.gc.ca/publicat/ccdr-rmtc/16vol42/dr-rm42-8/ar-02-eng.php. 